\title{
Correction to: Generalized Models and Non-classical Approaches in Complex Materials 2
}

Holm Altenbach, Joël Pouget, Martine Rousseau, Bernard Collet and Thomas Michelitsch

\section{Correction to:}

H. Altenbach et al. (eds.), Generalized Models

and Non-classical Approaches in Complex Materials 2, Advanced Structured Materials 90, https://doi.org/10.1007/978-3-319-77504-3

The original version of the book was inadvertently published without chapter 15 .

\footnotetext{
The updated online version of the book can be found at https://doi.org/10.1007/978-3-319-77504-3
}

The online version of chapter 15 can be found at https://doi.org/10.1007/978-3-319-77504-3_15 